\title{
CPD for community urologists
}

\section{Nasir Mahmood, MD}

Western Memorial Regional Hospital, Corner Brook, NL, Canada

Cite as: Can Urol Assoc J 2015;9(11-12):370. http://dx.doi.org/10.5489/cuaj.3473

Published online December 14, 2015

$\mathrm{T}$ hey come in different sizes, colours, creeds, and shapes, but what is common to all urologists - and particularly to community urologists - is they all tend to be friendly, funny, and happy surgeons. For some unknown reason, most tend to be male; only $8 \%$ of urologists in Canada are female.

Between their busy practice, demanding call coverage, and desire to keep administration and patients pleased, urologists also have to find time for continuous professional development (CPD). CPD not only helps with licensure renewal requirements, but is also a way to reinvigorate our academically deprived community with knowledge about new technology and other innovations. Moreover, it provides an excellent opportunity to network with colleagues.

The challenges faced by community oncologists are multifaceted and include:

a) Lack of sufficient funds to cover the costs of CPD conferences, as there is no compensation for time away from work to attend meetings

b) Unavailability of quality CPD resources locally

c) Busy clinical practice and call coverage commitments, denying them time to get to meetings of their choosing

d) Lack of incentives to pile up continuing medical education (CME) hours

e) Non-academic atmosphere at the local community hospital

Some CPD resources include:

a) Conferences: I have found annual meetings of Canadian Urological Association, American Urological Association, and European Association of Urology to be most useful. For globetrotters, a more comprehensive list of international urology meetings can be found at www.medical.theconferencewebsite.com/conferences/urology or www.urotoday.com/calendar.html

b) CUA (www.cua.org): CUA is accredited by the Royal College of Physicians and Surgeons of Canada (RCPSC) as a provider of CPD activities. Accordingly, the CUA is able to review and provide certification of Section 1 (group learning) and Section 3 (self-assessment pro-

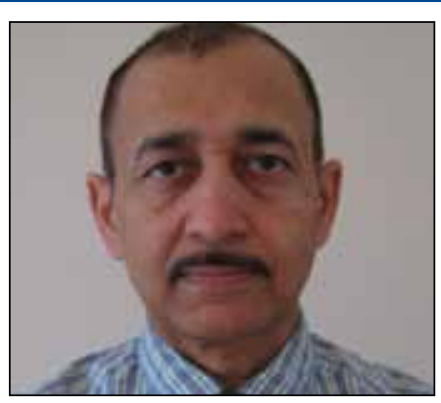

grams) learning activities, as defined by the Maintenance of Certification of the Royal College of Physicians and Surgeons of Canada. The CUA also offers a CPD grant program to support community urologists in initiatives that fulfill the objectives of the CUA scholarship fund (CUASF), which includes the encouragement of higher standards and qualifications in urology in Canada (http:// www.cua.org/en/cuasf-cpd).

c) University of Toronto (www.cpd.utoronto.ca/urology): University of Toronto organizes a yearly seminar providing an in-depth update of various topics in clinical urology.

d) Urology journals (www.mdlinx.com/urology/journals.cfm)

e) RCPSC (http://www.royalcollege.ca/portal/page/portal/rc/ members/cpd/cpd_accreditation/self_assessment_programs)

f) Canadian Medical Protective Association (https://www. cmpa-acpm.ca/home)

g) Canadian Medical Association (https://www.cma.ca)

h) Mobile phone apps (i.e. AUA guidelines, Medscape CME \& Education, Urology Times, and Uro Challenge to name a few).

Some suggestions to encourage community urologists to participate in CPD and enjoy it, include:

- Increase funding by the local hospitals, urology foundations, or other sources

- Strengthen CUA role in educational activities for community urologists, possibly with a separate forum at the CUA Annual Meeting

- Encourage academic urologists to provide regular community-based conferences

- Provide incentives for conference attendance (a lottery draw to attend a meeting for free; earn CME points and after collecting a certain amount of points, become eligible for free attendance at another CPD)

- Develop a website and cell phone app for community urologist interactions

Competing interests: The author declares no competing financial or personal interests.

Correspondence: Dr. Nasir Mahmood, Western Memorial Regional Hospital, Corner Brook, NL, Canada; nmnasirmahmood@gmail.com 